\title{
Broad ligament Pregnancy: A Report of Two CASES
}

\author{
M. A. Abdul ${ }^{1}$, A. M. Tabari ${ }^{2}$, D. Kabiru ${ }^{3}$ and N. Hamidu ${ }^{4}$ \\ ${ }^{1}$ Department of Obstetrics and Gynaecology Ahmadu Bello University Teaching Hospital Zaria Nigeria \\ ${ }^{2}$ Department of Radiology Aminu Kano University Teaching Hospital Kano, Nigeria \\ ${ }^{3}$ Department of Obstetrics and Gynaecology Federal Medical Centre Katsina, Nigeria \\ ${ }^{4}$ Department of Radiology Ahmadu Bello University Teaching Hospital, Zaria, Nigeria. \\ Reprint requests to: Dr. M. A. Abdul, Department of Obstetrics and Gynaecology Ahmadu Bello University \\ Teaching Hospital, Zaria, Nigeria. E-mail: maabdul90@yahoo.com
}

\begin{abstract}
Broad ligament pregnancy is a rare event and diagnosis is often late in our setting. Two multiparous women in early thirties presented for routine antenatal care. Routine ultrasonography revealed midtrimester abdominal pregnancies. Broad ligament pregnancy was diagnosed in both cases at laparotomy and both had excision of pregnancy and salpingo-ophorectomy with satisfactory recovery. Ultrasonography is a useful tool in the early diagnosis of abdominal pregnancy in our environment. Routine ultrasonography in pregnancy is advocated in our setting.
\end{abstract}

Key words: Broad ligament, pregnancy, ultrasonography

\begin{abstract}
Résumé
La grossesse de large ligament est rare, et parfois le diagnostique est tard. Deux femmes d'environ trente ans font des soins ante natals de routine. D'après une ultrasonographie de routine, elle a eu une grossesse abdominale de mi-trimestre. On a diagnostique une grossesse de large ligament dans les deux cas de laparotomie, et on a excisé la grossesse et elle a regagné la santé après même le salpinghoophorectomie. L'ultrasonographie est un moyen utile de diagnostiquer la grossesse abdominale. Nous proposons donc une ultrasonographie de routine pour les femmes enceintes.
\end{abstract}

Mots clés: large ligament, la grossesse, ultrasonographie

\section{Introduction}

Abdominal pregnancy is a rare but life threatening condition, which poses considerable challenge particularly to care provider in developing economies. ${ }^{1}$ In the tropics particularly sub-Saharan Africa, it is diagnosed in advanced stage of pregnancy in majority of cases ${ }^{1,2}$ Abdominal pregnancy accounted for about one percent of ectopic pregnancies. $^{3-5}$ It can occur in any part of the abdomen but commonly in the Pouch of Douglas and infrequently in the broad ligament and the ovary. 2,6
Pregnancy in the liver and the sigmoid colon respectively has been reported. ${ }^{7,8}$

Routine ultrasonography in pregnancy in our setting has perhaps changed the pattern of presentation of abdominal pregnancy with resultant early diagnosis and reduction of morbidity and mortality. Before the advent of sonography in subSaharan Africa, late presentation was the rule with some patients giving history of passing fetal bones via the rectum. ${ }^{9}$

This is a report of two patients with intraligamentum pregnancies seen in two tertiary 
centers in Northern Nigeria.

\section{Case 1}

A 29-year-old gravida 7 para $6^{+0}(5$ alive) who presented at the gynecologic clinic of Federal Medical Centre Katsina, Nigeria on the $23^{\text {rd }}$ of January 2004 with 8-months of amenorrhea and feeling of index pregnancy not growing like her previous pregnancies and not feeling fetal movements. The only significant finding on examination was a non-tender 22 weeks pelvic firm mass with most of its part in the left iliac fossa. Ultrasonoghaphy revealed a non-viable 22 weeks fetus outside the uterus in the left iliac fossa. She was counseled for laparotomy. At laparotomy, a left broad ligament pregnancy was evident and excision of the ectopic pregnancy and left salpingoophorectomy effected. Her post-operative course was uneventful. At three months of follow up she was doing well and had resumed menses three weeks earlier.

\section{Case 2}

A 33-year-old gravida $7 \operatorname{para6}^{+0}$ (6 alive) who presented at the booking clinic of Federal Medical Centre, Azare, Nigeria on the 23rd of November 2004 with six months pregnancy. Routine obstetric scan revealed an empty bulky uterus and a non-viable fetus in the right iliac fossa. A right-sided broad ligament pregnancy was diagnosed at laparotomy and she had excision of the ectopic gestation and right salpingo-ophorectomy. Postoperative events were satisfactory and she was discharged on the 7th postoperative day. At six months of follow up she was doing well and having regular menses.

\section{Discussion}

Broad ligament pregnancy as a form of ectopic pregnancy is a rare event particularly with spontaneous conception. Apantaka and colleagues reported a case of intraligamentum pregnancy following in-vitro fertilization in a patient with previous bilateral salpingectomy. ${ }^{10}$ Twin gestation in the broad ligament following both spontaneous and in-vitro fertilization have also been reported. ${ }^{11,12}$ Our two cases followed spontaneous conception. Most cases of broad ligament pregnancy were diagnosed in the first and early second trimester. ${ }^{3-5,10-12}$ Occasionally advanced intraligamentum pregnancies are encountered in our setting. ${ }^{13}$ Deneke reported a term broad ligament pregnancy associated with a live baby in Ethopia. ${ }^{13}$ Heterotrophic pregnancy involving the broad ligament has been reported. ${ }^{14}$ In the present report, diagnosis was made in the second trimester using ultrasonography.

Treatment of intraligamentum involves open laparotomy with excision of the pregnancy especially in advanced cases. Successful treatment using laparoscopy in early cases has been reported. ${ }^{4,5}$ Ultrasonography is a useful tool in the early diagnosis of abdominal and routine use in pregnancy should be the rule rather than the exception in our setting.

\section{References}

1. Rahaman J, Berkowitz R, Mitty H, Gaddipati S, Brown B, Nezhat F. Minimally invasive management of advanced abdominal pregnancy. Obstet Gynecol. 2004;103:1064-1068.

2. Hassim AM. Ectopic pregnancy. In: Lawson JB, Harrison KA, Bergstrom S (Eds). Maternity care in developing countries. RCOG Press, London. 2001; 295-301.

3. Paternoster DM, Santarossa C. Primary abdominal pregnancy: a case report. Minerva Ginecol. 1999;51:251-253.

4. Morita Y, Tsutsumi O, Kuramochi K, Momoeda M, Yoshikawa H, Taketani Y. Successful laparoscopic management of primary abdominal pregnancy. Hum Reprod. 1996;11:2546-2547.

5. Siow A, Chern B, Soong Y. Successful laparoscopic treatment of an abdominal pregnancy in the broad ligament. Singapore Med J. 2004;45:88-89.

6. Reziel A, Schachter M, Mordechai E, Friedler S, Panski M, Ron-El R. Ovarian pregnancy: a 12 year experience of 19 cases in one institution. Eur J Obstet Gynecol Reprod Biol. 2004;114:92-96.

7. Ganeshselvi P, Cherian D, Champ S, Myerson N. Primary abdominal pregnancy implanted on the sigmoid colon. J Obstet Gynaecol. 2003;23:667.

8. Chui AK, Lo KW, Choi PC, Sung MC, Lau JW. Primary hepatic pregnancy. ANZ J Surg. 2001;71:260-261.

9. Taifour SM. Expulsion of the fetal bones through the rectum after abdominal pregnancy. $\mathrm{Br} \mathrm{J}$ Obstet Gynaecol. 2004;111:626-627.

10. Apantaka $O$, Rana $P$, Inglis $T$. Broad ligament ectopic pregnancy following in-vitro fertilization in a patient with previous bilateral salpingectomy. J Obstet Gynaecol. 2006;26:474.

11. Phupong V, Tekasakal P, Kankaew K. Broad ligament twin pregnancy: A case Report. J Reprod Med. 2001;46:144-146.

12. Deshphande N, Matters A, Acharya U. Broad ligament twin pregnancy following in-vitro fertilization. Hum Reprod. 1999;14:854.

13. Deneke F. Advanced abdominal pregnancy in an Ethiopian mother. East Afr Med J. 1997;74:535536.

14. Atalla RK, Murphy PC, Balachandar C. Combined intrauterine and broad ligament ectopic pregnancy. J Obstet Gynaecol. 1997;17:203. 